\title{
Effect of Fasting during Ramadan on Migraine Sufferers
}

\author{
Wael M. Gabr ${ }^{1}$, Enaase A. M. E. Barakat ${ }^{2}$, Mohamed E. E. Shams ${ }^{3}$ \\ ${ }^{1}$ Department of Neurology, Faculty of Medicine, University of Mansoura, Mansoura, Egypt \\ ${ }^{2}$ Department of Internal Medicine, Faculty of Medicine, University of Mansoura, Mansoura, Egypt \\ ${ }^{3}$ Department of Pharmaceutics, Faculty of Pharmacy, University of Mansoura, Mansoura, Egypt \\ Email: waaael@yahoo.com
}

Received May 20, 2013; revised June 25, 2013; accepted July 9, 2013

Copyright (C) 2013 Wael M. Gabr et al. This is an open access article distributed under the Creative Commons Attribution License, which permits unrestricted use, distribution, and reproduction in any medium, provided the original work is properly cited.

\begin{abstract}
Background: Fasting during Ramadan in Muslim communities is distinct from regular voluntary or experimental fasting. Its consequent caffeine withdrawal, stress and low blood glucose level (hypoglycemia) may trigger headache in patients with migraine. Objectives: The main aim of this study was to evaluate the effect of the Ramadan fasting on the frequency of migraine attacks among observant Muslim migraine sufferers. Material and Methods: This research study was based on fasting Muslims; both genders were aged between 18 and 65 years. Fifty migraineurs were selected, participated and gave consent at Internal Medicine and Neurology Clinics in Riyadh National Hospital, KSA. Those patients were recruited over three consecutive months of Ragab, Shaban and Ramadan during the period of 2010 and 2013. The effect of fasting and special eating pattern during the month of Ramadan compared with the preceding two months (Ragab and Shaban) was studied. The primary parameters used for comparisons were migraine attack count, duration of migraine attacks in days, attack duration and severity of the attacks. Results: Only forty three migraine sufferers completed the current study to the end, 4 patients of them were males $(9.3 \%)$ and 39 were females $(90.7 \%)$. They were aged between 18 and 44 years (Mean $\pm \mathrm{SD}, 30.9 \pm 6.9$ years). Most of the fasting migraineurs during Ramadan were caffeine drinkers $(n=36,83.7 \%)$, cigarette smokers $(n=2,4.6 \%)$, overweight or obese (with BMI $>25) n=27$, $62.8 \%)$, under stress $(\mathrm{n}=29,67.4 \%)$ and with low to moderate physical activities (No exercise) $(\mathrm{n}=31,72 \%)$. The worst time for the fasting individuals was afternoon between 2:00 PM to 4:30 PM because majority of them had headache during these hours. This study showed a significant reduction in migraine attack count, number of headache days, number of attacks with acute medication and total medication intake among migraineurs during the month of Ramadan compared with the two pre-Ramadan months. However, attack severity and attack duration did not change significantly between all three months. Conclusion: In conclusion, the present study did not find any negative effects of fasting during Ramadan on the migraine sufferers.
\end{abstract}

Keywords: Migraine; Fasting; Hypoglycemia; Migraine in Ramadan

\section{Introduction}

Migraine is a highly prevalent and disabling sub-type of primary headache [1] and a benign neurological disorder [2]. It is an often intermittent severely disabling headache disorder that involves the neuronal and vascular system $[3,4]$. It has a prevalence of about $14 \%$ of women and $6 \%$ of men worldwide [5]; around a third (31\%) of these people report frequent migraines defined as three or more attacks a month [6]. Migraine causes severe impairment or bed rest in more than half (57\%) of affected people, markedly impairs quality of life both during and between attacks, increases absenteeism and reduces productivity at work, and is associated with increased healthcare costs. $[7,8]$ Frequent migraine is also a risk factor for progres- sion from episodic migraine to chronic migraine (at least 15 headache days a month) [9], which commonly presents as debilitating daily or near daily headaches [10].

Fasting for approximately one month is an obligatory practice for Muslims during the month of Ramadan. Fasting during this month is one of the five fundamental rituals of Islam. Muslims neither eat nor drink anything during this month, between dawn and sunset [11]. Fasting may last $11-20 \mathrm{~h}$ depending on geographical location and season. Following hunger during the abovementioned period, at sunset people usually eat a large meal, and pray for a long time, which requires some effort. Before dawn, people have a meal (Sahoor) and then perform their morning prayers. Many people who fast over Ramadan suffer mild or moderate headaches as a result 
of some factors such as caffeine withdrawal, stress and smoking cessation. Also fasting and consequent low blood sugar (hypoglycemia) may trigger headaches in patients suffering from migraine. Previous studies have shown that 50 percent of migraineurs have headaches after 16 hours without food [12,13]. Altered levels of serotonin and norepinephrine and dilation of blood vessels around the brain and scalp are the probable mechanisms of hunger-triggered headaches. Following the ingestion of an excessive carbohydrate load, a vascular headache may also occur in response to a rapid insulin secretion and reactive lowering of blood sugar [14].

The effects of fasting on humans have not been adequately investigated despite the fact that it concerns the Muslim community of more than one billion people. Ramadan fasting is a great opportunity for scientific research due to its peculiar nature. Ramadan fasting has some probable negative effects on sick people; the obligation that the daily calorie intake be taken in 1 or 2 meals instead of 3 to 5 has adverse effects [15]. For this reason, we attempted in the current research study to evaluate the effect of the Ramadan fasting on the frequency of migraine attacks among observant Muslim migraine sufferers.

\section{Methods}

\subsection{Set-Up}

The study was carried out at Internal Medicine and Neurology Clinics in Riyadh National Hospital, Riyadh, Saudi Arabia, over three consecutive Ramadans (2010, 2011 and 2012). It had been approved by the scientific committee at Riyadh National Hospital and with the Helsinki Declaration of 1975, as revised in 1983. Informed consent was taken from the patients to participate in this study.

\subsection{Patients}

\section{Inclusion criteria:}

For inclusion in the study, the patients should satisfy the following criteria: 1) age 18 - 65 years; 2) diagnosis of primary migraine headaches (point 1 of ICHD-II); 3 ) adequate cognitive and expressive ability to understand the questionnaire and take part in the study.

\section{Exclusion criteria:}

Patients were excluded from participating in the current study when they had secondary headaches or other types of headache, intracranial disorder, other than migraine, head trauma in the previous year, pregnancy or lactation during study period.

\subsection{Diagnosis}

Diagnosis of migraine was made according to the criteria of the International Classification of Headache Disorders, 2nd edition [16]. Migraine without aura was defined as a self reported history of severe headache lasting for more than four hours but less than three days, which occurred on one or both sides of the head, and was associated with feeling sick, finding loud noises or bright lights unpleasant, or both. Migraine symptoms which had ever been accompanied by visual disturbance, abnormalities of speech, skin sensation, or muscle power were defined as migraine with aura.

\subsection{Questionnaire}

Face-to-face interviews were based on a semi-structured questionnaire that included the required information bout migraine attacks during Ramadan and the preceding two months (Ragab and Shaban). Other variables such as age, sex, socioeconomic status (SES), cigarette smoking habits, frequency of headache and migraine and associated factors were added.

Patients were asked about the following items: 1) the duration and frequency of migraine attacks during Ramadan and the two preceding months; 2) necessity to take medications for the acute attack; 3) the number of acute medications needed; 4) the severity of each attack as measured by visual analogue scale (VAS) from no pain $(=0)$ to worst pain imaginable $=10$. The interview and the diagnostic questionnaire for headache were given to patients during the examination and were based on patients' answers. During the visit, an accurate physical and neurological examination was performed. Blood tests or neuroimaging were used when indicated to rule out a secondary headache.

\subsection{Statistical Analysis}

The primary parameters used for comparisons were migraine attack count, duration of migraine attacks in days, mean attack duration, median attack severity (in VAS score from 0 - 10), number of migraine attacks with acute medication and total medication intake during Ramadan and the preceding two months.

The data were analyzed by computer using the statistical package SPSS for windows version 19 (software). Statistical analyses included parametric tests to compare means (paired and unpaired two sample t-test), non-parametric tests to compare medians (Wilcoxon test and Mann-Whitney test) and Chi-square test. For all tests $\mathrm{P}$ values $<0.05$ were considered to be statistically significant.

\section{Results}

Forty three migraine sufferers completed the current study to the end from a total of fifty patients (13 patients at 
2010, 17 patients at 2011 and 23 patients at 2012). Thirty nine were females $(90.7 \%)$ and four were males $(9.3 \%)$. Ages varied from 18 years to 44 years (mean \pm SD, 30.9 \pm 6.9 years). The measured lifestyle among studied patients are summarized in Figure 1. Their mean migraine duration was $10 \pm 6$ years (range, 1 - 23 years) (Table 1). All patients were using acute attack medication for migraine attacks and twenty eight of them were also using preventive medication.

The parameters of headache and medication are shown in Tables 1 and 2. By comparing these parameters in Ragab and Shaban (the two months preceding Ramadan) to Ramadan, there was a statistically significant reduction in attack count, number of headache days, number of attacks with acute medication and total medication intake whilst no significant change observed between the Ragab and Shaban month (Table 2).

However, attack severity and attack duration did not change significantly between all three months (Table 2). By comparing percentage differences during Ramadan to the preceding two months (Ragab, Shaban), attack count, number of headache days, number of attacks with acute medication and total medication intake showed significant reduction (Table 3 ).

\section{Discussion}

A predominance of female patients $(90.7 \%)$ with migraine was observed in this study. The mean age of onset was higher in females than in males, in concordance with the findings reported by Stewart et al and Victor et al. $[17,18]$ However; this finding should be interpreted with caution because of the small number of male patients and potential bias in our study.

The exact pathophysiology of migraine is still unclear [19] but clinical experience and many electrophysiological studies demonstrated an increased sensitivity of the brain of the migraineur [20-24]. It is therefore not surprising that in this sensitized brain migraine may be triggered by external and internal stimuli. Identification of environmental factors (including dietary factors) that consistently trigger migraine in some subjects may be helpful to reduce attacks frequency. Fasting as trigger for migraine is frequently reported. Some migraineurs show reactive hypoglycaemia due to diet-induced hyperinsulinism [25].

Although many studies showed that fasting or skipped meals was significantly more common among dietary triggers, with frequency of $40 \%$ to $82 \%$ of patients re-

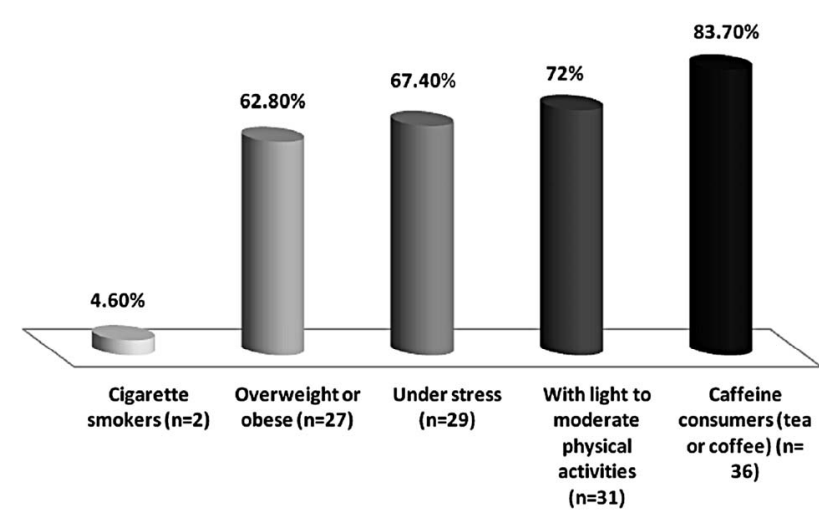

Figure 1. The lifestyle of migraine sufferers $(n=43,100 \%)$.

Table 1. Demographic and headache characteristics.

\begin{tabular}{cccc}
\hline & Females & Males & Total \\
\hline Number & 39 & 4 & 43 \\
Age (years) (mean \pm SD) & $31.08 \pm 7.2$ & $29.75 \pm 3.3$ & $30.95 \pm 6.9$ \\
Duration of migraine (years) (mean \pm SD) & $10.27 \pm 6.3$ & $8.0 \pm 6.1$ & $10.28 \pm 6.4$ \\
\hline
\end{tabular}

Table 2. Headache and medication parameters during study period.

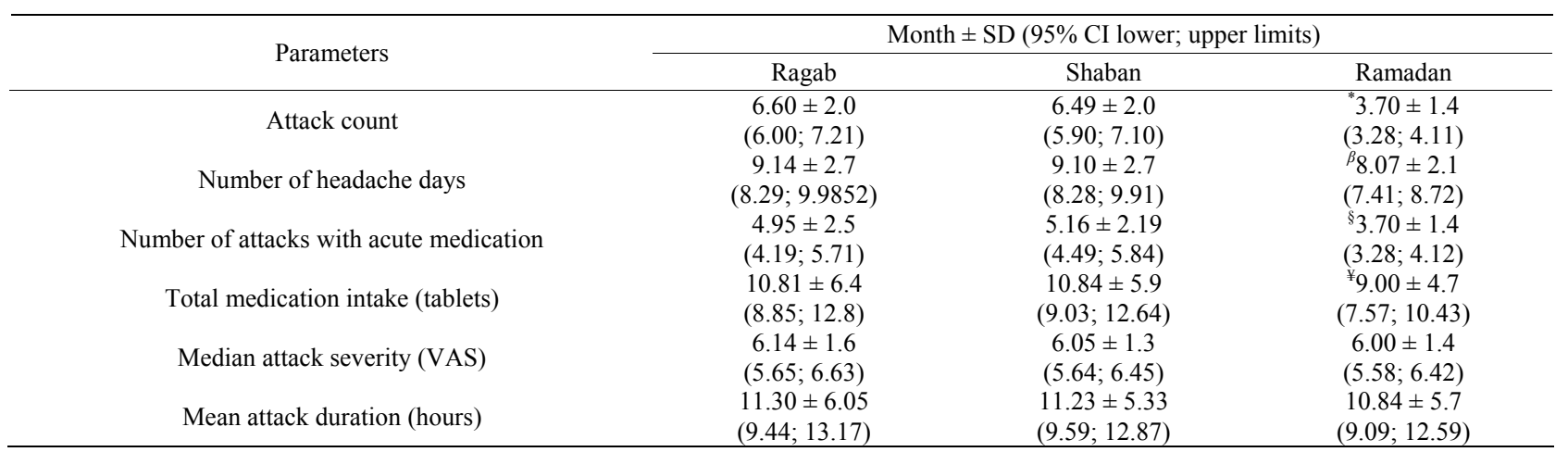

${ }^{*} \mathrm{P}<0.001 / \mathrm{P}<0.001 ;{ }^{\beta} \mathrm{P}<0.03 / \mathrm{P}<0.02 ;{ }^{\S} \mathrm{P}<0.003 / \mathrm{P}<0.001 ;{ }^{\ddagger} \mathrm{P}<0.003 / \mathrm{P}<0.008$ in Paired t-test/Wilcoxon signed test (with $95 \%$ confidence intervals) comparing Ramadan with the preceding two months (differences are statistically significant). 
Table 3. Percentage difference of parameters compared to Ramadan.

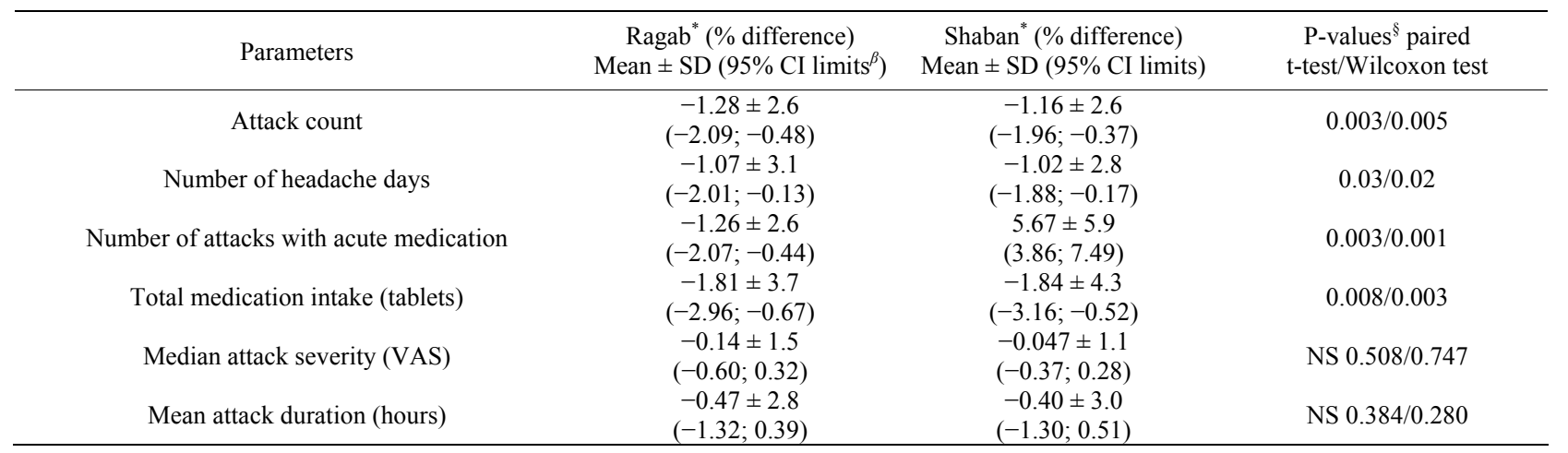

${ }^{*}$ Percentage difference from baseline period; ${ }^{\beta}$ (lower; upper) limits of $95 \%$ confidence interval; ${ }^{\S} \mathrm{P}$-values with $95 \%$ confidence interval; NS: not significant.

porting fasting as a trigger for migraine attacks. [21,26, 27], our study found that the migraine attacks significantly decreased in number during Ramadan in which Muslims fasts about 11 to 20 hours a day. This may be due to the fact that in most of the studies fasting was transient event and in most cases due to skipped meals but in Ramadan the situation is different as the fasting is daily for about 28 to 30 continuous days and this is associated with changing the feeding habits so that food is regularly consumed in fixed time every day and also there is a reduction in the number of meals from the regular 3 meals in most individuals to only two meals (Fotoor and Sahoor). Moreover, the meal is followed by physical exercise in the form of praying for longer periods of time which ranging from few minutes to many hours in most of individuals. In contrast to our result, Ibrahim Furthermore, in another research study [28], it was found that the prevalence of the headache during the month of Ramadan was $76.6 \%$ and after Ramadan was $73.7 \%$ among a total of 898 studied subjects and there were not any negative effects of fasting during Ramadan on the migraine and headache frequencies except sleeping disorders. These findings in turn are in agreement with our results.

A significant reduction of a total medication intake during Ramadan to control acute attacks was found and this may be partially due to the fact that most of migraine attacks occurring during the period of fasting mostly before food intake and also due to the reduction of the attacks numbers and the days of the attacks.

A positive association between fasting and severe migraine was found by Chakravarty et al. [29], however, a recent study has contradicted this association [30]. Also no significant association between the fasting and migraine severity was found in our study.

Physicians and clinical pharmacists treating Muslim migraine patients should discuss the issue with their patients and ask about the patients previous Ramadan experiences, and adapt the patient management accordingly.
They have to highlight caffeine withdrawal as the most common cause of headache while fasting. Patients can often prevent headaches by reducing caffeine consumption in the weeks leading up to Ramadan month, while a cup of strong coffee just before the start of the fast for the day may prevent caffeine withdrawal headache. Hypoglycaemia (low blood sugar) can also trigger headaches in many people. If a meal with high sugar content is taken before the days fast begins, it can cause a rapid rise in blood sugar levels followed by a fast drop that may trigger a headache. Eating a meal with low sugar content before the fast may prevent the onset of a headache during the day. Dehydration is another common trigger, adequate intake of fluid before the onset of the fast can often prevent headaches. The human brain is more than $75 \%$ water, and it is very sensitive to the amount of water available to it. When the brain detects that the water supply is too low, it begins to produce histamines. This is essentially a process of water rationing and conservation, in order to safeguard the brain in case the water shortage continues for a long period of time. The histamines directly cause pain and fatigue, in other words a headache and the low energy that usually accompanies it. Patients should also, as far as possible, try to avoid exposure to other triggers such as fluid retention, stress, smoking, fatigue and lack of sleep during Ramadan, when there is a greater tendency to experience headache and migraine. In high risk patients (especially those with a history of Ramadan-associated migraine exacerbations), pharmacological treatment should be discussed with the patients. The treatment should preferably be once daily (because of the Ramadan schedule) and without long titration periods. The use of the antiepileptic long-acting valproic acid preparation, taken once daily or any other preventive therapy could be prescribed for migraine like one of antidepressants (amitriptyline or fluoxetine), beta-blockers (propranolol or timolol), calcium channel blockers like verapamil, NSAIDs like ketoprofen, naproxen/naproxen sodium or serotonin antagonists like 
cyproheptadine.

From the previous, it is concluded that the present results corroborate the importance of searching for alternative solutions for migraine prophylaxis; it is important to consider non-pharmacological options, such as dietary changes and changing patients' lifestyle. However, it is also important to educate patients about potential factors based on scientific evidence, focusing on those factors that can be modified. Therefore, longitudinal prospective and controlled studies are required to prove the experimental and actual relationships between migraine and its precipitating factors, especially dietary ones, as well as possible interactions between factors [31].

\section{Conclusion}

In conclusion, the present study did not find any negative effects of fasting during Ramadan on the migraine sufferers.

\section{REFERENCES}

[1] "The International Classification of Headache Disorders: 2nd Edition," Cephalalgia, Vol. 24, Suppl. 1, 2004, pp. 9160.

[2] C. Waeber and M. A. Moskowitz, "Therapeutic Implications of Central and Peripheral Neurologic Mechanisms in Migraine," Neurology, Vol. 61, No. 8, 2003, pp. S9S20. doi:10.1212/WNL.61.8 suppl 4.S9

[3] P. J. Goadsby, R. B. Lipton and M. D. Ferrari, "Migraine-Current Understanding and Treatment," New England Journal of Medicine, Vol. 346, 2002, pp. 257270. doi:10.1056/NEJMra010917

[4] R. B. Lipton, W. F. Stewart, S. Diamond, M. L. Diamond and M. Reed, "Prevalence and Burden of Migraine in the United States: Data from the American Migraine Study II," Headache, Vol. 41, No. 7, 2001, pp. 646-657. doi:10.1046/j.1526-4610.2001.041007646.x

[5] N. Schmitz, F. Admiraal-Behloul, E. B. Arkink, et al., "Attack Frequency and Disease Duration as Indicators for Brain Damage in Migraine," Headache, Vol. 48, No. 7, 2008, pp. 1044-1055. doi:10.1111/j.1526-4610.2008.01133.x

[6] T. J. Steiner, K. Paemeleire, R. Jensen, et al., "European Principles of Management of Common Headache Disorders in Primary Care," Journal of Headache and Pain, Vol. 8, Suppl. 1, 2007, pp. S3-S47.

[7] M. C. Kruit, L. J. Launer, J. Overbosch, M. A. van Buchem and M. D. Ferrari, "Iron Accumulation in Deep Brain Nuclei in Migraine: A Population-Based Magnetic Resonance Imaging Study," Cephalalgia, Vol. 29, No. 3, 2009, pp. 351-359. doi:10.1111/j.1468-2982.2008.01723.x

[8] E. Hazard, J. Munakata, M. E. Bigal, M. F. Rupnow and R. B. Lipton, "The Burden of Migraine in the United States: Current and Emerging Perspectives on Disease Management and Economic Analysis," Value Health, Vol. 12 , No. 1, 2009, pp. 55-64.

\section{doi:10.1111/j.1524-4733.2008.00404.x}

[9] J. Olesen, M. G. Bousser, H. C. Diener, et al., "New Appendix Criteria Open for a Broader Concept of Chronic Migraine," Cephalalgia, Vol. 26, No. 6, 2006, pp. 742746. doi:10.1111/j.1468-2982.2006.01172.x

[10] A. I. Scher, L. A. Midgette and R. B. Lipton, "Risk Factors for Headache Chronification," Headache, Vol. 48, No. 1, 2008, pp. 16-25. doi:10.1111/j.1526-4610.2007.00970.x

[11] A. H. Sakr, "Fasting in Islam," Journal of the American Dietetic Association, Vol. 67, 1975, pp. 17-21.

[12] J. N. Blau, "Migraine Triggers: Practice and Theory," Pathologie Biologie (Paris), Vol. 40, 1992, pp. 367-372.

[13] J. M. Hockaday, D. H. Williamson and C. W. Whitty, "Blood-Group Levels and Fatty-Acid Metabolism in Migraine Related to Fasting," Lancet, Vol. 297, No. 7710, 1971, pp. 1153-1156. doi:10.1016/S0140-6736(71)91662-X

[14] J. W. Lance and M. Anthony, "Some Clinical Aspects of Migraine. A Prospective Survey of 500 Patients," Archives of Neurology, Vol. 15, No. 4, 1966, pp. 356-361. doi:10.1001/archneur.1966.00470160022003

[15] M. Aslam and A. Assad, "Drug Regimens and Fasting during Ramadan: A Survey in Kuwait," Public Health, Vol. 100, No. 1, 1986, pp. 49-53. doi:10.1016/S0033-3506(86)80086-5

[16] Headache Classification Committee of the International Headache Society, "Classification and Diagnostic Criteria for Headache Disorders, Cranial Neuralgias and Facial Pain," Cephalalgia, Vol. 8, Suppl. 7, 1988, pp. 1-96.

[17] T. W. Victor, X. Hu, J. C. Campbell, D. C. Buse and R. B. Lipton, "Migraine Prevalence by Age and Sex in the United States: A Life-Span Study," Cephalalgia, Vol. 30, No. 9, 2010, pp. 1065-1072. doi: $10.1177 / 0333102409355601$

[18] W. F. Stewart, M. S. Linet, D. D. Celentano, N. M. Van and D. Ziegler, "Age- and Sex-Specific Incidence Rates of Migraine with and without Visual Aura," American Journal of Epidemiology, Vol. 134, 1991, pp. 1111-1120.

[19] M. Aguggia, G. D'Andrea and G. Bussone, "Neurophysiology and Neuromodulators," Neurological Sciences, Vol. 28, Suppl. 2, 2007, pp. S97-S100. doi:10.1007/s10072-007-0759-3

[20] J. N. Blau, "Migraine Triggers: Practice and Theory," Pathologie Biologie (Paris), Vol. 40, 1992, pp. 367-372.

[21] E. L. Spierings, A. H. Ranke and P. C. Honkoop, "Precipitating and Aggravating Factors of Migraine versus Tension-Type Headache," Headache, Vol. 41, No. 6, 2001, pp. 554-558. doi:10.1046/j.1526-4610.2001.041006554.x

[22] F. C. Rose, "Trigger Factors and Natural History of Migraine," Functional Neurology, Vol. 1, 1986, pp. 379384.

[23] V. Van den Bergh, W. K. Amery and J. Waelkens, "Trigger Factors in Migraine: A Study Conducted by the Belgian Migraine Society," Headache, Vol. 27, No. 4, 1987, pp. 191-196. 
[24] L. Kelman, "The Triggers or Precipitants of the Acute Migraine Attack," Cephalalgia, Vol. 27, No. 4, 2007, pp. 394-402. doi:10.1111/j.1468-2982.2007.01303.x

[25] C. Finocchi and G. Sivori, "Food as Trigger and Aggravating Factor of Migraine," Neurological Sciences, Vol. 33, 2012, Suppl. 1, pp. S77-S80.

[26] P. T. Fukui, T. R. Goncalves, C. G. Strabelli, et al., "Trigger Factors in Migraine Patients," Arquivos de NeuroPsiquiatria, Vol. 66, No. 3a, 2008, pp. 494-499. doi:10.1590/S0004-282X2008000400011

[27] N. Karli, M. Zarifoglu, N. Calisir and S. Akgoz, "Comparison of Pre-Headache Phases and Trigger Factors of Migraine and Episodic Tension-Type Headache: Do They Share Similar Clinical Pathophysiology?" Cephalalgia, Vol. 25, No. 6, 2005, pp. 444-451. doi:10.1111/j.1468-2982.2005.00880.x

[28] A. Bener, A. Azhar and M. Bessisso, "Do Fasting and Eating Habits in Ramadan Affect Migraine, Headache and Sleep Disorders," Journal of Nutrition \& Food Sciences, Vol. 37, p. 7.

[29] A. Chakravarty, A. Mukherjee and D. Roy, "Trigger Factors in Childhood Migraine: A Clinic-Based Study from Eastern India," Journal of Headache and Pain, Vol. 10, No. 5, 2009, pp. 375-380. doi:10.1007/s10194-009-0147-x

[30] A. Milde-Busch, A. Blaschek, I. Borggrafe, F. Heinen, A. Straube and R. von Kries, "Associations of Diet and Lifestyle with Headache in High-School Students: Results from a Cross-Sectional Study," Headache, Vol. 50, No. 7, 2010, pp. 1104-1114.

[31] R. F. Camboim, K. Castro, V. R. de Oliveira, P. A. da Silveira, M. L. Fagundes Chaves and I. D. Schweigert Perry, "Perceived Migraine Triggers: Do Dietary Factors Play a Role?" Nutrición Hospitalaria, Vol. 27, No. 2, 2012, pp. 483-489. 